\title{
Geographic Information System (GIS) capabilities in traffic accident information management: a qualitative approach
}

\author{
Maryam Ahmadi ${ }^{1}$, Ali Valinejadi ${ }^{2}$, Afshin Goodarzi ${ }^{3}$, Ameneh Safari ${ }^{4}$, Morteza Hemmat ${ }^{5}$, Hesamedin Askari \\ Majdabadi $^{6}$, Ali Mohammadi ${ }^{7}$
}

${ }^{1}$ Ph.D. of Health Information Management, Professor, Department of Health Information Management, School of Health Management and Information Sciences, Iran University of Medical Sciences, Tehran, Iran

${ }^{2} \mathrm{Ph} . \mathrm{D}$. of Health Information Management, Assistant Professor, Social Determinants of Health Research Center, Semnan University of Medical Sciences, Semnan, Iran

${ }^{3}$ M.Sc. of Nursing, Department of Emergency Medicine, Faculty of Paramedics, Kermanshah University of Medical Sciences, Kermanshah, Iran

${ }^{4}$ M.Sc. of Health Information Technology, Department of Research Management Office, Faculty of Paramedics, Kermanshah University of Medical Sciences, Kermanshah, Iran

5 Ph.D. of Health Information Management, Assistant Professor, Department of Health Information Technology, School of Nursing, Saveh University of Medical Sciences, Saveh, Iran

${ }^{6} \mathrm{PhD}$ of Health, Assistant professor, Nursing care research center, Semnan University of Medical Sciences, Semnan, Iran

${ }^{7}$ Ph.D. of Health Information Management, Assistant Professor, Department of Health Information Management, Faculty of Paramedics, Kermanshah University of Medical Sciences, Kermanshah, Iran

\section{Type of article: Original}

\begin{abstract}
Background: Traffic accidents are one of the more important national and international issues, and their consequences are important for the political, economical, and social level in a country. Management of traffic accident information requires information systems with analytical and accessibility capabilities to spatial and descriptive data.

Objective: The aim of this study was to determine the capabilities of a Geographic Information System (GIS) in management of traffic accident information.

Methods: This qualitative cross-sectional study was performed in 2016. In the first step, GIS capabilities were identified via literature retrieved from the Internet and based on the included criteria. Review of the literature was performed until data saturation was reached; a form was used to extract the capabilities. In the second step, study population were hospital managers, police, emergency, statisticians, and IT experts in trauma, emergency and police centers. Sampling was purposive. Data was collected using a questionnaire based on the first step data; validity and reliability were determined by content validity and Cronbach's alpha of $75 \%$. Data was analyzed using the decision Delphi technique.

Results: GIS capabilities were identified in ten categories and 64 sub-categories. Import and process of spatial and descriptive data and so, analysis of this data were the most important capabilities of GIS in traffic accident information management.

Conclusion: Storing and retrieving of descriptive and spatial data, providing statistical analysis in table, chart and zoning format, management of bad structure issues, determining the cost effectiveness of the decisions and prioritizing their implementation were the most important capabilities of GIS which can be efficient in the management of traffic accident information.

Keywords: Geographic Information System; Information management; Information Systems; Accidents, Traffic
\end{abstract}

Corresponding author:

Assistant Professor Dr. Ali Mohammadi, Department of Health Information Management, Faculty of Paramedics, Kermanshah University of Medical Sciences, Kermanshah, Iran.

Tel: +98.8338279697, Fax: Email: a.mohammadi@kums.ac.ir

Received: December 09, 2016, Accepted: March 16, 2017, Published: June 2017

iThenticate screening: February 15, 2017, English editing: May 02, 2017, Quality control: May 12, 2017

(C) 2017 The Authors. This is an open access article under the terms of the Creative Commons Attribution-NonCommercialNoDerivs License, which permits use and distribution in any medium, provided the original work is properly cited, the use is non-commercial and no modifications or adaptations are made. 


\section{Introduction}

Each year almost 1.3 million people die in traffic accidents globally, and about 20 to 50 million people are injured (1). The first leading cause of death among all accidents is road traffic accidents (2). According to the annual report of the WHO in 2015, traffic accidents are responsible for $8.1 \%$ of deaths and they are considered as the third leading cause of deaths in Iran and the first cause of deaths among people aged 15-45 years (3). Statistics and information are essential for programming and surveys on traffic accidents. The key factors to study consist of location and time of crash, climate, driver's specifications, vehicle specification, site and severity of damage to vehicle, driver, passenger and pedestrian. These data should be well gathered and analyzed in order to find out the main causes of crashes (4). Traffic accidents data are substantial for the analysis process, so it is indispensable to have the capability of data management for a successful analysis (5-11). Applying technology that relates descriptive data of accidents to their locations would provide better understanding. Considering the involvement of various factors and organizations in traffic accidents, this issue confronts more complexities $(12,13)$. The Geographic Information System (GIS) emphasizes on providing services in location scale (14) and it simply enables the operators to use spatial information and descriptive data to make plans, tables and diagrams. This system properly provides search tools; data analysis and results display (15). GIS is a management and decision support system that contains descriptive data and location maps which is fruitful for traffic accident information management (16-18). Thus, regarding the quantity and variety of data in road accidents and rescue teams, the authentic analysis of data without using GIS is feasible (19). Traffic accidents as predictable and preventable incidents are one of the most remarkable problems in transportation. One of the most effective ways to overcome these problems is proper management of resources and facilities in addition to adoption of necessary measures in the shortest time possible through identifying the accident-prone situations and factors. Therefore, traffic and crashes management and prevention are considered as capabilities of GIS in transportation (20). In line with problems of traffic accidents, wide-spreading roads and unexpected increasing dangers, deploying rescue teams on roads is essential. In order to provide rescue services, it is needed to determine the best and the shortest distance between two spots of services supply and demand. The main objective of rescue stations is to bring about nationwide road security consistent with predetermined objectives. Hence, to realize this objective it is needed to have an integrated overview by using GIS (21). Location scanning of rescue stations is one of the fundamental actions in traffic accident control. Besides, establishing road rescue stations is a substantial step in accident management by using GIS (22). After a rescue demand, the wisest action is to find the shortest way between rescue station and the crash site, because using traditional rescue systems result in a delay that may cause negative outcomes. However, in modern transportation after a rescue demand, the crash site and specifications are imported into the GIS and then the routing of some factors including traffic jams, intersections and obstacles, physical characteristics of routes, the shortest time possible, and the wisest rescue direction, are specified and they are announced to the rescue teams (23). Growth of data gathering, helping the stations with decision making, establishing a location information system to rescue, and routing to and from traffic accidents are all the factors that in various situations, provide a systematic and reasonable correlation among stations and rescue teams (22). Nowadays, the possibility of accidents, especially road crashes, is inevitable; thereupon, crash reduction and control is needed. Since most road accident data and factors are geographical and spatial, using GIS can be helpful for crash reduction and control $(24,25)$. So, in order to use GIS in traffic accident information management, knowing its capabilities and the expectations of each involved group from its capabilities, can be advantageous. Thus, regarding the fact that traffic accident information management systems in Iran consist of unlinked police stations, emergency centers and hospitals and these systems do not work based on GIS; the present study is going to specify GIS capabilities in traffic accident information management.

\section{Material and Methods}

This quality appraisal cross-sectional study was carried out in two phases by Decision Delphi technique in 2016. The first phase entailed identifying GIS capabilities. In this phase, the research resources for identifying the capabilities of traffic accident information management based on GIS consisted of retrieved essays, documents, books, thesis, guides and reports from internet and library data banks. In this phase, sampling was not done and all retrieved resources with entrance criteria based on search strategy (Table 1) were assessed. Retrieved documents from search results were studied and the data which were related to GIS capabilities in traffic accident information management were all collected by using a form designed for elicitation of capabilities. GIS capabilities for traffic accident information management, analysis, reporting, location scanning and other issues in traffic accident information management were classified and their subsets were extracted. They were imported in capabilities collecting form, and they were presented in descriptive charts. The study of related resources was continued thoroughly until there were no more new cases of GIS capabilities in management and analysis. GIS capabilities in traffic accident information management were categorized in ten groups: 1) Capabilities of saving and retrieving 
accident data; 2) capabilities and tools for accident analysis; 3) capabilities and editing functions of accidents; 4) capabilities of using various databases; 5) capabilities of system designing, user interface (UI) designing and graphical user interface (GUI) designing; 6) management capabilities and tools; 7) capabilities for output and reporting; 8) analysis capabilities of access to health care and evaluation of access evaluation; 9) identifying health services location; 10) capabilities of decision support for location finding. Information resources to save traffic accident information include the traffic police department and surveillance system department. The surveillance system entails a center for accident management, medical emergency and hospital (26). The second phase of study was assigned to specify GIS capabilities in traffic accident information management, traffic research environment, trauma and medical emergency. Research population included experts in traffic accidents, statistics and IT in the traffic police department, managers of hospitals and clinical wards, the chief of health, traffic information management department, agent to record traffic accidents, agent to register accident costs in accounting units of trauma centers, general manager, IT experts and emergency technicians in medical emergency centers. Purposive sampling was done and subjects were selected through easy access and random method. The sample size is shown in Table 2. Data collecting tools for questionnaire had ten groups and 100 subgroups which were provided based on the first phase results. For each subgroup, five columns were designed based on importance from one to five (no importance $=1$, low importance $=2$, mean importance $=3$, high importance $=4$, ultra high importance $=5$ ). They were designed for sample size to specify the importance of capability. At the end of each capability group, an empty row was inserted for more capabilities which were not mentioned. It was inserted to add them in the questionnaire. The content validity of the questionnaire was considered and based on the idea of clinical personnel, (1 physician, 2 nurses and 2 technicians), a computer engineer, police and manager of health information system, five subjects were determined by each. Cronbach's Alpha interpretation determined 0.75 as reliability. Questionnaires were presented by in-person visits of researchers, and sending express mail and e-mails. Data analysis was done by using Decision Delphi technique in order to reach a consensus about achieving $75 \%$ or more for choices of "high importance $=4$ " and "ultra-high importance $=5$ ". The first-round results of questionnaire were obtained and the frequency of each capability was calculated for the choices of "high importance $=4$ " and "ultra-high importance $=5$ ". In the first round of Delphi, the capabilities which gained the importance of less than 50\% were omitted. Those that gained 50-75\% went to the second round of Delphi and those with $75 \%$ and more were considered as GIS capabilities in traffic accident information management. The agreement was reached for all choices after the second round of Delphi.

Table 1. Search strategy and criteria to identify GIS capabilities in traffic accident information management

\begin{tabular}{|c|c|c|}
\hline \multicolumn{2}{|c|}{ Sites, Criteria, Strategy } & Descriptions, Characteristics \\
\hline \multirow{2}{*}{\multicolumn{2}{|c|}{ Websites }} & http://www.who.int \\
\hline & & http://www.esri.com \\
\hline \multicolumn{2}{|c|}{ Search engines } & Yahoo, Google, Google scholar \\
\hline \multicolumn{2}{|c|}{ Databases } & $\begin{array}{l}\text { Pub Med, ISI Web of Science, Scopus, EMBASE, IEEE, Cochrane, SID, Magiran, } \\
\text { Civilica (up to 2016, May, 30) }\end{array}$ \\
\hline \multirow[t]{2}{*}{$\begin{array}{l}\text { Selection } \\
\text { criteria }\end{array}$} & $\begin{array}{l}\text { Inclusion } \\
\text { criteria }\end{array}$ & $\begin{array}{l}\text { Literature in the English and Persian language. } \\
\text { Papers, reports, guidelines, instructions, books and thesis of research published up to } \\
\text { July } 2016 \text {, in the full text, from valid sources, with a clearly stated purpose, }\end{array}$ \\
\hline & $\begin{array}{l}\text { Exclusion } \\
\text { criteria }\end{array}$ & $\begin{array}{l}\text { Non-peer- reviewed papers, reports and forms, retrieved from personal weblogs and } \\
\text { abstracts with inaccessible full text. }\end{array}$ \\
\hline \multicolumn{2}{|l|}{ Strategy } & $\begin{array}{l}\text { GIS AND "Health care", "Analysis of ambulance crash data", GIS AND "Traffic } \\
\text { accident information system", GIS AND "Physical accessibility", GIS AND "Analysis } \\
\text { tools", GIS AND "Health research", "GIS capabilities", GIS AND "Reports tools", GIS } \\
\text { AND "Crash Referencing" OR "Analysis System", GIS AND "Traffic records", "Data } \\
\text { representations" AND GIS, GIS AND modeling, GIS AND "Decision Support", GIS } \\
\text { and "Road traffic analyses" OR "Crash analyses" }\end{array}$ \\
\hline
\end{tabular}


http://www.ephysician.ir

Table 2. The number of sample size in centers

\begin{tabular}{|c|c|c|c|}
\hline Row & Center & Organization/Department/ specialty & Numbers \\
\hline \multirow[t]{3}{*}{1} & \multirow[t]{3}{*}{ Police department } & Accident investigator officer & 20 \\
\hline & & Statistics expert & 8 \\
\hline & & IT expert & 8 \\
\hline \multirow[t]{5}{*}{2} & \multirow[t]{5}{*}{ Trauma center } & Manager & 8 \\
\hline & & Supervisor of trauma ward & 12 \\
\hline & & Chef of health information management department & 8 \\
\hline & & In charge of traffic accidents information registration & 8 \\
\hline & & In charge of accidents costs registration & 8 \\
\hline \multirow[t]{4}{*}{3} & \multirow[t]{4}{*}{ Emergency center } & Manager & 8 \\
\hline & & Statistics expert & 8 \\
\hline & & IT expert & 8 \\
\hline & & Emergency technician & 15 \\
\hline \multicolumn{3}{|l|}{ Total } & 119 \\
\hline
\end{tabular}

\section{Results}

In the first phase of study, 100 capabilities in ten groups were specified for a traffic accident information system based on GIS. Then these capabilities were polled. In the first phase, 55 capabilities had the score of over 75 and they confirmed; 22 capabilities had below 50 scores and they were omitted; 23 capabilities were from 50 to 75 which were polled in the second phase. In the second phase, 14 out of 23 capabilities were omitted because they were below 50 and 9 capabilities were over 75. Finally, 64 capabilities that GIS can have in traffic accident information management were selected as ultimate capabilities. The omitted capabilities were those that were not efficient in traffic accident information management. GIS capabilities for traffic accident information management after two stages of Delphi technique and, according to the opinion of sample size, are demonstrated in Table 3. In this table, considering the use and ability of GIS in various fields related to traffic accident issues, the capabilities were divided into ten categories.

Table 3. GIS capabilities in traffic accidents information management

\begin{tabular}{|l|l|}
\hline $\begin{array}{l}\text { Saving \& } \\
\text { retrieving } \\
\text { accident data }\end{array}$ & $\begin{array}{l}\text { Capability of saving and retrieving descriptive, spatial and graphical data related to organizations } \\
\text { related to accident }\end{array}$ \\
\cline { 2 - 3 } & $\begin{array}{l}\text { Capability of saving and retrieving descriptive, spatial and graphical data related to service } \\
\text { providers for casualties }\end{array}$ \\
\cline { 2 - 3 } Accident & Saving and retrieving data related to effective factors in accidents \\
\cline { 2 - 3 } analysis tools & $\begin{array}{l}\text { Saving and retrieving data of disease, surgery, treatment costs and other data related to accident } \\
\text { casualties }\end{array}$ \\
\cline { 2 - 3 } & Statistical analysis of accident data \\
\cline { 2 - 3 } & Analysis of access to service centers in specific route or area \\
\cline { 2 - 3 } & Specifying the nearest and the best center to transfer casualties \\
\cline { 2 - 3 } & Specifying emergency centers in black spot areas and to equip them \\
\cline { 2 - 3 } & $\begin{array}{l}\text { Presenting more precise reports of accidents and road specifications while using GPS } \\
\text { accidents, route, casualties, hospitals, disease, surgery, treatment cost, emergency center and other } \\
\text { charts }\end{array}$ \\
\cline { 2 - 3 } & Using spot analysis to evaluate accidents based on the spot or intersection in a specified area \\
\cline { 2 - 3 } & Strip analysis to assess accidents in just one direction \\
\cline { 2 - 3 } $\begin{array}{l}\text { Cluster analysis to cluster study accidents around one road characteristic e.g. bridge, railway } \\
\text { intersection, traffic light, road signs }\end{array}$ \\
\cline { 2 - 3 } & Sliding scale analysis to identify black spots \\
\cline { 2 - 3 } & Analysis by using inquiry maker \\
\cline { 2 - 3 } & $\begin{array}{l}\text { Using network analyzer for optimum use of road network, in study: average setting of departure } \\
\text { time, one way streets, no entry directions, overpass \& underpass, closed streets }\end{array}$ \\
\cline { 2 - 3 } & Testing various assumptions in traffic accident management and road safety \\
\hline & Link to the scanned file of accident design and image of accident site, and comparing them to \\
\hline
\end{tabular}




\begin{tabular}{|c|c|}
\hline \multirow{2}{*}{$\begin{array}{l}\text { functions of } \\
\text { accidents }\end{array}$} & assess topographic features and signs \\
\hline & $\begin{array}{l}\text { Editing geological effects and location maps for analyzing and testing assumptions related to } \\
\text { accident }\end{array}$ \\
\hline \multirow[t]{4}{*}{$\begin{array}{l}\text { Using various } \\
\text { databases }\end{array}$} & $\begin{array}{l}\text { Capability of communication, exchange, import and export of data with Access, SQL, Excel } \\
\text { databases }\end{array}$ \\
\hline & $\begin{array}{l}\text { Capability of communication and exchange of data with hospital database, drivers' characteristics, } \\
\text { vehicles characteristics }\end{array}$ \\
\hline & $\begin{array}{l}\text { Capability of communication with spatial databases related to roads, land use, emergency centers, } \\
\text { hospitals }\end{array}$ \\
\hline & $\begin{array}{l}\text { Capability of communication with and using databases of accidents, casualties, lighting } \\
\text { conditions, climate, road surface condition, intersections, demographic data \&location } \\
\text { demographics }\end{array}$ \\
\hline \multirow{11}{*}{$\begin{array}{l}\text { Designing } \\
\text { system, } \\
\text { designing UI } \\
\text { \& GUI }\end{array}$} & Providing import functions for accident data in an electronic pre-defined format \\
\hline & Designing export for graphical show, charts and diagrams of data \\
\hline & Designing the system with a minimum place for leaving comments \\
\hline & Designing an open, user friendly and simple UI \\
\hline & Designing step by step guidelines for all actions of operators \\
\hline & Designing metadata for all fields and the system descriptive $\&$ spatial data \\
\hline & Designing a data manager module to facilitate import and export of data \\
\hline & Recording a raster image to share the same data for organizing and managing accident models \\
\hline & Using model's module to estimate and evaluate the effects of programming for accidents \\
\hline & Using output module to show and print the results for each model \\
\hline & Using user-name and password for system \\
\hline \multirow[t]{5}{*}{$\begin{array}{l}\text { Management } \\
\text { tools }\end{array}$} & $\begin{array}{l}\text { Programming for specifying transportation route, creating new routes, finding suitable places to } \\
\text { build health care centers }\end{array}$ \\
\hline & Simultaneous support of various operators while working with traffic accident information system \\
\hline & $\begin{array}{l}\text { Specifying cost effectiveness of decisions related to accident, roads, rescue and services using } \\
\text { GIS }\end{array}$ \\
\hline & $\begin{array}{l}\text { Guiding and helping stakeholders and policy makers to promote road safety and traffic accident } \\
\text { management }\end{array}$ \\
\hline & Identifying black spots that emerge as the priority of amending actions \\
\hline \multirow[t]{7}{*}{$\begin{array}{l}\text { Exports \& } \\
\text { reports }\end{array}$} & $\begin{array}{l}\text { Presenting outcomes of analysis and report of descriptive data and geography of accidents in } \\
\text { charts, diagrams and plans }\end{array}$ \\
\hline & $\begin{array}{l}\text { Presenting various statistical charts \& diagrams with plans for reporting the saved variables for } \\
\text { accident }\end{array}$ \\
\hline & Integrating data and graphic images related to accidents \\
\hline & $\begin{array}{l}\text { Presenting outcomes of accident related assumptions in plans, graphical diagrams and tabular text } \\
\text { files }\end{array}$ \\
\hline & $\begin{array}{l}\text { Capability of presenting emergency information about the effect of suggestions and alternative } \\
\text { policies in the stages of designing and decision making of accident related systems }\end{array}$ \\
\hline & Making various combinations from accident and geographic data \\
\hline & Showing black spots according to given criteria (simple and complicated) \\
\hline \multirow{7}{*}{$\begin{array}{l}\text { Analysis } \\
\text { capability of } \\
\text { access to } \\
\text { health care \& } \\
\text { access } \\
\text { evaluation }\end{array}$} & Assigning casualties lists to their residence place and accident site \\
\hline & $\begin{array}{l}\text { Simulating health needs for emergency and health care centers according to one area's data for } \\
\text { the others }\end{array}$ \\
\hline & $\begin{array}{l}\text { Using spatial statistical methods such as estimation of central density for evaluating availability of } \\
\text { services, and assessing the frequency distribution of distances }\end{array}$ \\
\hline & Making topography to identify mountainous and impassable areas \\
\hline & Evaluating transferring time of casualties according to type and quality of road \\
\hline & Estimating transferring time in road network from the crash site to the nearest emergency center \\
\hline & Assessing geographical assumptions in areas and allocating resources and services to them \\
\hline \multirow{3}{*}{$\begin{array}{l}\text { Identifying } \\
\text { health } \\
\text { services }\end{array}$} & Prioritizing in establishing and developing health care centers and emergency centers \\
\hline & Assessing the effectiveness of emergency services in real time \\
\hline & Linking ambulance location data to a data set including place, time, response time and type of \\
\hline
\end{tabular}




\begin{tabular}{|c|c|}
\hline \multirow[t]{6}{*}{ location } & contact \\
\hline & Providing maps and images for development and improvement of ambulance positioning \\
\hline & Identifying the best locations for establishing emergency and health care centers \\
\hline & Finding the shortest routes and ambulance GPS \\
\hline & Identifying the shortest routes for ambulances during rush hour \\
\hline & $\begin{array}{l}\text { Analyzing emergency services by using accident site data to assess ambulances location and } \\
\text { finding the nearest one }\end{array}$ \\
\hline \multirow{3}{*}{$\begin{array}{l}\text { Capability of } \\
\text { spatial } \\
\text { decision } \\
\text { support }\end{array}$} & Assessing the effect of environmental factors and roads on accidents \\
\hline & $\begin{array}{l}\text { Merging geographical database, database management system, inquiry, UI and analysis tools such } \\
\text { as assigning location model and location interaction models for decision support }\end{array}$ \\
\hline & Considering unstructured issues \\
\hline
\end{tabular}

\section{Discussion}

Road safety is a serious national and international issue and its consequences are important for the political, economic and social level in a country. Traffic accident information is extremely beneficial in analysis of road crashes, rescuing the impaired, decision making for managers and policy makers of the health care system. The high trend of road crashes brings out so much information that their management requires high technology $(16,27,28)$. Recent progressions in geomatics cause more concentration on studies about development and use of geographic information tools for road safety. GIS simultaneously manages a large amount of spatial and descriptive data, and it provides various processing capabilities and analytical tools for spatial data. It also facilitates reporting, data analysis and retrieving effective factors in road safety. It identifies the factors that cannot be found through usual statistical methods and generally, it results in reliable decisions and more concentration on surveys that make optimum use of available resources. GIS increases the collaboration of all involved sections and partners in safety on the roads, and provides an integrated language to show and describe the data (29). Therefore, in Iran and other countries, many studies have been done by using GIS capabilities in traffic accidents. In the present study, stakeholders of traffic accident management specified the capabilities of decision making support for resolving illstructured issues and measuring the effects of environmental factors on accident rates. Also, the following capabilities of this system were important for involved members of traffic accident management: management tools for specifying the routes and place of new centers, supporting various operators, determining the cost the effectiveness of decisions and prioritizing them. These capabilities were used in several studies. In a study done by Sambrani, it is shown that recent improvements in executive researches and information technology have provided the condition of integrating executive research techniques and GIS. This integration can be used in development of spatial decision support systems in transportation. In analysis of routes for choosing the most effective direction (the best and the shortest) and choosing and analyzing alternative routes in the condition of human made or natural disasters, GIS provides a medium for spatial information of database in order to save the spatial and descriptive data. The relation between the medium and database provides the operator the possibility of asking questions about spatial, descriptive and combined data (29). Baraklianos et al. have done a survey in Greece in which the objective was resolving the problems of data management and decision support in road safety. In Greece, crash data are collected by various agents and organizations such as police departments, hospitals, emergency centers and insurance companies. Databases of these organizations are not connected to each other. So, it results in the noncompliance and over-collecting of data that leads to the waste of time and information. Moreover, using road accident data is basically limited to statistical aims and it brings their limited partnership in decision making. Thus, GIS is actually a proper tool to manage traffic accident data and it supports decision making for traffic accidents (30). Haji Housainlou et al. identified the effective factors, and estimated their importance in the intersections crashes. They studied various criteria through ranking analysis, ratio analysis, analysis hierarchy process and weighting case to compare the criteria and their buffers. They identified the safest and the most dangerous intersections of Tehran (20). Kalantari et al. carried out a study in which they did a spatial analysis of intracity crashes and etiology of effective spatial factors by using GIS. The analysis of findings indicated that most accidents took place in administrative, educational and recreational directions due to their vast space, more traffic and popularity (31). In this study, GIS capabilities which were important for managers comprised of saving and retrieving spatial and descriptive data of organizations and involved people, factors and consequences of traffic accidents, capability of various statistical analysis and zoning for having access to stations and services, determining the shortest routes, black spots, and analysis of special characteristics such as specific injuries, people, days, intersections and climatic conditions. Moreover, another GIS capability was an editing function to study terrain accidents and a locations map for testing the assumptions related to accidents. People involved in traffic accidents 
considered them essential for accident management. Using GIS in promoting road safety is seen in the study of Soleimani et al., in which GIS and its capabilities are identified as the best solution in collecting, saving and presenting geographic information related to traffic accidents. Spatial data are substantial in GIS, and GPS as a positioning system in finding and solving traffic problems in GIS can promote the safety of roads (32). Finding the best places for establishing emergency centers, police stations, hospitals, finding black spots and assessing the effectiveness of services according to the location of involved centers are all special capabilities of GIS which are specified for traffic accident information management in this study. The following capabilities are also among GIS capabilities: presenting local dispersion pattern for hospital services, finding the best place to build a medical emergency center, allocating and distributing resources (budget, human resource, equipment), creating an efficient communication network for various health care centers, helping evidence based decision making, navigating for quick and on-time rescue in the condition of natural disasters and medical emergencies (33-36).

\section{Conclusions}

The important capabilities mentioned by operators were: using data from other databases, obtaining and transferring data from them, designing system for using various modules to evaluate the effects of programming and information showing in different methods, providing medium and data entry forms to facilitate the use of this system. To sum up, policy making and programming for the prevention and reduction of traffic accidents requires the technology that links descriptive and spatial data, and it also does the spatial analysis of these data. So, it can be efficiently used in traffic accident information management.

\section{Acknowledgments:}

Special thanks to all the participants in this study.

\section{Conflict of Interest:}

There is no conflict of interest to be declared.

Authors' contributions:

All authors contributed to this project and article equally. All authors read and approved the final manuscript.

\section{References:}

1) World Health Organization. Global status report on road safety: supporting a decade of action for road safety, 2011-2020. Geneva: 2013.

2) Peden M, Scurfield R, Sleet D, Mohan D, Hyder AA, Jarawan E, et al. World report on road traffic injury prevention Geneva: World Health Organization; 2004.

3) World health statistics 2015. World Health Organization; 2015.

4) World Health Organization. World Report on Road Traffic Injury Prevention. 1 ed. Tehran: Transportation Research Center; 2007. 95.

5) lai PC, Chan WY. GIS for Road Accident Analysis in Hong Kong. Geographic information Sciences. 2004; 10(1): 58-67. doi: 10.1080/10824000409480655.

6) Cindy G, Janice F, Suzanne W. Geographic Information Systems (GIS) In Health Organizations: Emerging Trends for Professional Education. The California Geographer 49, (c) 2009 by The California Geographical Society. 2009; 49: 82-107.

7) Shanmugasundaram J, Soulalay V, Chettiyappan V. Geographic information system-based healthcare waste management planning for treatment site location and optimal transportation routeing. Waste Manag Re. 2012; 30(6): 587-95. doi: 10.1177/0734242X11427941. PMID: 22128092.

8) Galway L, Bell N, Sae AS, Hagopian A, Burnham G, Flaxman A, et al. A two-stage cluster sampling method using gridded population data, a GIS, and Google Earth(TM) imagery in a population-based mortality survey in Iraq. Int J Health Geogr. 2012; 11: 12. doi: 10.1186/1476-072X-11-12. PMID: 22540266, PMCID: PMC3490933.

9) Helbich M, Leitner M, Kapusta ND. Geospatial examination of lithium in drinking water and suicide mortality. Int J Health Geogr. 2012; 11: 19. doi: 10.1186/1476-072X-11-19. PMID: 22695110, PMCID: PMC3441892.

10) Kamel Boulos MN, Berry G. Real-time locating systems (RTLS) in healthcare: a condensed primer. Int J Health Geogr. 2012; 11: 25. doi: 10.1186/1476-072X-11-25. PMID: 22741760, PMCID: PMC3408320.

11) Fei $S$, Wei D, Bing $Z$. Traffic Information Management and Promulgating System Based on GIS Digital Manufacturing and Automation (ICDMA), 2012 Third International Conference on; GuiLin: IEEE; 2012; 994-7. 
12) World Health Organization. Global status report on road safety 2013. Luxembourg; 2013.

13) World Health Organization. Global Plan for the Decade of Action for Road Safety, 2011-2020. Geneva: 2010.

14) National Institute for Health Research. Application of science and technology of remote sensing and GIS in the health sector. application of science and technology of remote sensing and GIS in the health sector; Tehran: Tehran University; 2010.

15) Saif A, Rashidi M, Roozbahani R, Dehdashti N, Poursafa P. GIS applications in medical research strategy for disease prevention. quarter of Han main journal of medicine. 2011; 29(164): 1-20.

16) Toosi AM, Rezvani MH, Atashi D. Application of GIS in relief road accidents. Geomatics: Tehran; 2007.

17) Jayan KD, Ganeshkumar B. Identification of Accident Hot Spots: AGIS Based Implementation for Kannur District, Kerala. International Journal of Geomatics and Geosciences. 2010; 1(1): 51-9.

18) Ganeshkumar B, Ramesh D. Emergency Response Management and Information System (ERMIS)-A GIS based software to resolve the emergency recovery challenges in Madurai city, Tamil Nadu. International Journal of Geomatic and Geosciences. 2010; 1(1): 1-13.

19) Kennedy M. Introducing Geographic Information Systems with ArcGIS. Third ed. United States of America: University of Kentucky; 2013.

20) Haji Housainlou M, Ebrahim Srst Y. Application of GIS in urban black spots within the network (case study of Tehran Region 2). Journal Environmental Science and Technology. 2009; 11(40): 275-85.

21) Patel AB, Waters NM, Blanchard IE, Doig CJ, Ghali WA. A validation of ground ambulance pre hospital times modeled using geographic information systems. International Journal of Health Geographics. 2012; 11(42). doi: 10.1186/1476-072X-11-42.

22) Mousavis S. the application of GIS systems in reducing accidents and improving road and Rescue Service. the National Conference of road accidents, accidents, rail and air. Zanjan: Zanjan University; 2011.

23) Morowati sharifabadi MA. The Health Belief Model Variables as Predictors of Risky Driving Behaviors among Commuters in Yazd, Iran. Traffic Injury Prevention. 2009; 10(5): 436-40. doi: 10.1080/15389580903081016.

24) Yaghoubzadeh N, Amiri P. presents a conceptual model for managing traffic black spots using GIS. 2nd National Conference of Roadway, Railway and Arial Accidents. Zanjan, Iran 2012.

25) Fone DL, Christie S, Lester N. Comparison of perceived and modelled geographical access to accident and emergency departments: a cross-sectional analysis from the Caerphilly Health and Social Needs Study. Int J Health Geogr. 2006; 5: 16. doi: 0.1186/1476-072X-5-16. PMID: 16613601, PMCID: PMC1526712.

26) Movahedi M, Severi H, Ainy E, Mehmandar MR. Comparative mapping information provided by the sources of information used in the model American and Asian. Payesh. 2011; 11(1): 21-7.

27) Sadat Hosseini SM, Soleimani M. Causes of death in a highway accident. Traffic Management Studies. 2009; 4(14): 71-84.

28) Zayrzadh A, Ahadi R. A comprehensive database of information on effective step towards reducing traffic accidents. Fourth National Congress on Civil Engineering: Tehran; 2008.

29) Sambrani VN. Geographic Information Systems (GIS) as Spatial Decision Support Systems (SDSS). Elixir International Journal. 2012; 50: 10406-9.

30) Baraklianos I, Spyridonidou A, Basbas S, Karanikolas N, Vagiona D. Developing A Gis-Based Methodology For Managing And Analyzing Road Traffic Accident Data In Greece. 4th International Conference on Cartography \& GIS; Albena, Bulgaria; 2012.

31) Kalantari M, Moradi Mofrad S. Spatial analysis of accident black spots in Zanjan. Rahvr Quarterly Research Studies. 2013; 2(4): 11-29.

32) Soleimani MR, Jahani T. Applications of GIS Software in Road traffic safty. Journal of Traffic Managegent Study. 2009; 4(14): 111-30.

33) Shoja Araghi M, Tavallaei S, Ziaeian P. Location Analysis Regarding Disaster Management Bases via GIS Case study: Tehran Municipality. 2011; 3(10): 41-60.

34) Cartographic N. Members of the National Council for GIS Strategic Plan For the years 2010 to 2014 Tehran: National Cartographic; 2009.

35) Bazemore A, Phillips RL, Miyoshi T. Harnessing geographic information systems (GIS) to enable community-oriented primary care. J Am Board Fam Med. 2010; 23(1): 22-31. doi: 10.3122/jabfm.2010.01.090097. PMID: 20051539.

36) Pasha I. Ambulance management system using GIS. Sweden: Linköping; 2006. 